\title{
Meio Ambiente, Impacto Ambiental e Desenvolvimento Sustentável: Conceituações Teóricas sobre o Despertar da Consciência Ambiental ${ }^{1}$
}

\author{
Environment, Sustainable Development and Environmental Impact: \\ theoretical conceptualizations about the Awakening of Environmental \\ Consciousness
}

Suellen Silva Pereira

Doutoranda em Recursos Naturais/Universidade Federal de Campina Grande Rua, Aprígio Veloso, 822, Bairro Universitário, CEP: 58.429-900, Fone: (83) 2101-1000, Campina

Grande, PB. e-mail: suellenssp@hotmail.com

\author{
Rosires Catão Curi \\ $D^{a}$ Systems Design Engineering - University of Waterloo, Canadá \\ Professora do Programa de Pós-Graduação em Recursos Naturais - PPGRN/UFCG \\ Rua, Aprígio Veloso, 822, Bairro Universitário, CEP: 58.429-900, Fone: (83) 3310-1290 \\ e-mail: rosires@dec.ufcg.edu.br
}

RESUMO

\begin{abstract}
As questões ambientais tornaram-se foco de discussões por todo o mundo. Busca-se alternativas de como desenvolver e ao mesmo tempo preservar a natureza, de modo a manter os recursos naturais disponíveis para as próximas gerações. Neste contexto, a presente comunicação se configura por ser um ensaio teórico, que busca refletir, a luz da literatura existente, a problemática ambiental, bem como evidenciar o despertar do ser humano para com as causas ambientais nas últimas décadas, ressaltando a importância da realização de eventos em prol do meio ambiente, a exemplo da Conferência Rio+20, para uma maior ampliação das discussões sobre a preservação ambiental. Para tanto, realizou-se uma pesquisa de gabinete, com base em alguns trabalhos considerados expoentes dessa temática, estruturando uma análise decadal das principais contribuições para a emergência da temática ambiental. Observa-se que, apesar das iniciativas em prol de um desenvolvimento pautado na sustentabilidade (econômica, social e ambiental) ainda se mostrarem incipientes, deve-se reconhecer que estas possuem maior visibilidade e aceitação por parte dos segmentos da sociedade, quando comparado há décadas atrás, ressaltando a importância da temática em questão nos dias atuais. Conclui-se que a década de 1990 redimensionou a percepção e prática das questões ambientais, especialmente devido à publicação da Agenda 21, importante instrumento de discussão em torno da temática ambiental, com vistas a um novo modelo de desenvolvimento para o séc. XXI, estando este pautado em uma sociedade sustentável.
\end{abstract}

Palavras-chave: Meio Ambiente, Desenvolvimento Sustentável, Consciência Ambiental.

\section{ABSTRACT}

Environmental issues have become a matter of discussion throughout the world. The aim is to develop alternatives while preserving nature in order to maintain the available natural resources for future generations. In this regard, this communication is configured to be a theoretical essay, which seeks to reflect the light of the existing literature, environmental issues, as well as highlight the awakening of the human toward environmental causes in recent decades, underscoring the importance of holding of events in favor of the environment, such as the Rio +20 Conference to further expand the discussions on environmental preservation. Therefore, we carried out a survey of staff, based on some works considered exponents of this theme, structuring a decadal analysis of the main contributions to the emergence of environmental issues. It is observed that despite the initiatives for development guided by the sustainability (economic, social and environmental) still fledgling show, it should be recognized that these have greater visibility and acceptance by segments of society compared decades ago, highlighting the importance of the issue in question today. We conclude that the 1990 resized the perception and practice of environmental issues, especially due to the publication of Agenda 21, an important tool

\footnotetext{
${ }^{1}$ Artigo recebido em 01.08.2012. Revisado por pares em 15.10.2012 (blind review). Reformulado em 29.11.2012. Recomendado para publicação em 17.12.2012 por José Ribamar Marques de Carvalho (Editor Científico). Publicado em 28.12.2012.
} 
for discussion of environmental issues, with a view to a new development model for the century. XXI, this being guided in a sustainable society.

Key-words: Environment, Sustainable Development, Environmental Awareness.

\section{INTRODUÇÃO}

Com a consolidação do sistema capitalista (que tem como uma de suas premissas a acumulação do capital e o incentivo ao consumo), a problemática ambiental ganha ênfase, se agravando a partir da década de 1980 com o surgimento do processo de Globalização, que tinha como objetivo homogeneizar as civilizações do mundo, colocando como base os moldes da população norte-americana.

Franco \& Druck (1998) tomam a Revolução Industrial como marco que revolucionou tanto as relações sociais - exercidas entre os homens no desempenho das atividades econômicas e na vida social - quanto às bases técnicas das atividades humanas - avanços científicos e sua aplicação industrial sob a forma de tecnologia - é possível compreender o processo deflagrado de crescente transformação da interação entre a humanidade e o planeta, isto é, entre as atividades humanas e a biosfera. A partir da Revolução Industrial - que se expandiu progressivamente da Inglaterra para o resto do mundo ocidental e, no século XX, se desdobra 'modernamente' no mundo oriental -, podem ser destacados elementos marcantes de transformação profunda na vida dos homens entre si e com o meio ambiente e, consequentemente, das condições objetivas e subjetivas da saúde humana e da sustentabilidade ambiental.

Diante das condições desenvolvimentistas acima descritas e, levando em consideração ao mau uso do meio ambiente, viu-se a necessidade de se fazer algo a esse respeito, dessa forma, surgiram vários movimentos e organizações em prol da preservação do meio ambiente e consequentemente, da manutenção da vida, tendo em vista que ambas as questões estão intrinsecamente relacionadas. O que pode ser percebido na fala de Barbieri (2003), quando o autor relata que a preocupação com os problemas ambientais decorrentes dos processos de crescimento e desenvolvimento deu-se lentamente e de modo muito diferenciado entre diversos agentes, indivíduos, governos, organizações internacionais, entidades da sociedade civil. [...] pode-se pensar numa evolução que seguiu as seguintes etapas. A primeira etapa baseia-se na preocupação de problemas ambientais localizados. Numa segunda etapa, a degradação ambiental é percebida como um problema generalizado, porém confinado nos limites territoriais dos estados nacionais. Na terceira etapa, a degradação ambiental é percebida como um problema planetário atingindo a todos e que decorre do tipo de desenvolvimento praticado pelos países.

Nesta perspectiva, pode-se dizer que a consciência sobre os problemas ambientais é muito recente, passando o mundo a se preocupar com os impactos gerados pelo mau uso dos recursos naturais, principalmente nas últimas décadas do século XX, sendo estes, atualmente, temas importantes e recorrentes, nos mais diversos segmentos de opinião. Waldman (2003) confirma essa assertiva quando afirma que o meio ambiente é tema prioritário nas agendas dos Chefes de Estado, Organizações Não- Governamentais (ONGs), populações tradicionais, grupos rurais e urbanos, sindicatos, empresas, associações comunitárias, administrações públicas.

REUNIR - Revista de Administração, Contabilidade e Sustentabilidade - Vol. 2, no 4, p.35-57, Set-Dez/2012.

ISSN: 2237-3667 
Indiscutivelmente, a crise ambiental é uma das questões fundamentais enfrentadas pela humanidade e exige a necessidade de uma mudança de mentalidade, em busca de novos valores e uma ética em que a natureza não seja vista apenas como fonte de lucro e passe, acima de tudo, a ser enfocada como meio de sobrevivência, para as espécies que habitam o Planeta, inclusive o homem (MARÇAL, 2005).

Nesta mesma compreensão, Ely (1998) nos relata que os problemas de poluição e degradação do Meio Ambiente levaram o ser humano a reconhecer que a qualidade do meio em que vivem é pré-requisito para o desenvolvimento econômico e tecnológico do país. Dessa forma, não há como melhorar a qualidade de vida, sem uma concomitante melhoria da qualidade ambiental.

De maneira geral, na medida em que as sociedades humanas se territorializaram construindo seus ambientes a partir de interações com espaços concretos de um planeta que possui grande diversidade de formas geológicas e biológicas -, emergiram incontáveis exemplos de práticas materiais e percepções culturais referidas ao mundo natural. A produção de um entendimento sobre esse mundo tornou-se um componente básico da própria existência social (PÁDUA, 2010).

Desse modo, faz-se extremamente necessário uma compreensão holística sobre o que vem a ser meio ambiente, como forma de integrar todos os elementos que influenciam no seu constante processo de transformação, almejando, a partir de então, novas relações com este meio na tentativa reestabelecer, principalmente, o seu processo de exploração superando a representação da natureza como um objeto, visão esta que desencadeou toda a problemática ambiental instaurada na atualidade. Pelo exposto, meio ambiente não tem apenas um sentido estático, como reforçado por Dulley (2004), haja vista ser constituído por relações dinâmicas entre seus elementos componentes, tanto vivos como não vivos.

Segundo Sgarbi et. al. (2008), os estudos sobre a sustentabilidade têm apresentado um crescente interesse na comunidade acadêmica, despertando não só o interesse dos estudiosos da área socioambiental, mas também dos pesquisadores de temas como estratégia, competição, gestão, dentre outros. Neste contexto, a presente comunicação se configura por ser um ensaio teórico, que busca refletir, a luz da literatura existente, a problemática ambiental, bem como evidenciar o despertar do ser humano para com as causas ambientais nas últimas décadas, através de uma sistematização dos principais acontecimentos que contribuíram para o tratamento da questão ambiental nas esferas científicas, sociais, políticas e econômicas, a exemplo da Conferência Rio+20, para uma maior ampliação das discussões sobre a preservação ambiental.

Buscando uma melhor compreensão das discussões propostas, o presente artigo se encontra estruturado em cinco momentos. Primeiramente, nesta parte introdutória, faz-se uma breve apresentação da temática proposta, assim como expõem-se os objetivos da pesquisa. Em seguida, encontra-se o aporte teórico, sendo este baseado em alguns termos norteadores, tais como: "meio ambiente", "impacto ambiental" e "desenvolvimento sustentável". Posteriormente, apresentam-se os procedimentos metodológicos utilizados para embasar o desenvolvimento das reflexões suscitadas para a presente comunicação. Os resultados e discussões aparecem logo em seguida, estando estes estruturados conjuntamente. Por fim, têm-se as considerações finais das informações apresentadas. 


\section{FUNDAMENTAÇÃO TEÓRICA}

\subsection{Meio Ambiente: Considerações Iniciais}

Quando se fala em problemas ambientais, ainda é muito recorrente que algumas pessoas os relacionem a situações que, normalmente, acontecem distante da sua realidade, do seu cotidiano, a exemplo da extinção de animais, desmatamentos, derretimento das calotas polares, desertificação, dentre outros. Tal concepção pode esta relacionada à visão e/ou concepção reducionista que muitos possuem sobre o que seria o meio ambiente, bem como a ênfase midiática que vem sendo observada nas últimas décadas sobre a problemática ambiental, que normalmente, reduz tais problemas a alguns fatos isolados, descontextualizando a complexidade dos fenômenos e causas reais destes.

$\mathrm{O}$ que pode ser compreendido quando se analisa algumas conceituações sobre o que seria meio ambiente, como observado no trecho que se segue: Embora a distância não seja grande, ecologia e meio ambiente de forma alguma são sinônimos. A primeira, segundo uma definição que remonta a mais de um século, seria a "ciência da morada", a economia doméstica da natureza, por assim dizer. Seu objeto de estudo são as relações entre o organismo e o seu habitat. Meio ambiente, por sua vez - ou, mais elegantemente, o ecossistema -, vem a ser a própria morada (KLOETZEL, 2009, p. 14 - grifo nosso).

Analisando a citação acima evidenciada, pode-se verificar que o autor utiliza a conceituação de meio ambiente como sinônimo para ecossistema, o que reforça a ideia reducionista e simplista que muitos possuem sobre meio ambiente. Por este motivo, é comum que, quando questionados, estes elenquem uma série de elementos naturais ou belas paisagens para definir e/ou exemplificar o significado de meio ambiente, sempre relacionando estes elementos a externalidades em que estão inseridos, fato que corrobora para o descaso e/ou desconhecimento da gravidade que tais problemas ambientais podem ou poderão vir a repercutir na vida destes.

Por este motivo (necessidade de se tratar o ambiente integralmente e não somente parte dele), é que alguns autores, a exemplo do geógrafo Carlos Walter Porto Gonçalves ${ }^{2}$, propõe o abandono do termo meio ambiente, passando a adotar apenas ambiente na tentativa de minimizar as diferenças muitas vezes observadas, a começar por nossas próprias atitudes, haja vista que nem sempre compreendemos que somos animais e, por este motivo, somos elementos do meio.

Procurando compreender as conceituações sobre meio ambiente, haja vista que esta muitas vezes se confunde com os conceitos de natureza, ecologia, ou até mesmo ecossistema (como destacado anteriormente), encontramos algumas definições como forma de nortear as discussões ora propostas. Assim sendo, e levando em consideração a complexidade dos seus elementos constituintes, bem como das relações estabelecidas, o meio ambiente pode ser considerado:

Para Primavesi (1997), meio ambiente não é apenas o espaço em que se vive "mas o espaço do qual vivemos". Para Tostes (1994), "meio ambiente é toda relação, é

\footnotetext{
${ }^{2}$ Ver mais em: GONÇALVES, C. V. P. Os (des)caminhos do meio ambiente. 14 ed. São Paulo: Contexto, 2008. (Temas atuais).
}

REUNIR - Revista de Administração, Contabilidade e Sustentabilidade - Vol. 2, no 4, p.35-57, Set-Dez/2012.

ISSN: 2237-3667 
PEREIRA, S. S.; CURI, R. C. Meio Ambiente, Impacto Ambiental e Desenvolvimento...

multiplicidade de relações. É relação entre coisas, como a que se verifica nas reações químicas e físico-químicas dos elementos presentes na Terra e entre esses elementos e as espécies vegetais e animais; é a relação de relação, como a que se dá nas manifestações do mundo inanimado com a do mundo animado (...) é especialmente, a relação entre os homens e os elementos naturais (o ar, a água, o solo, a flora e a fauna); entre homens e as relações que se dão entre as coisas; entre os homens e as relações de relações, pois é essa multiplicidade de relações que permite, abriga e rege a vida, em todas as suas formas. Os seres e as coisas, isoladas, não formariam meio ambiente, porque não se relacionariam” (apud DULLEY, 2004, p. 18, 19 ).

Soma-se, as conceituações acima apresentadas, a definição descritiva de meio ambiente apresentada por Coimbra (2002), o qual define o meio ambiente como um conjunto de elementos abióticos (físicos e químicos) e bióticos (flora e fauna), organizados em diferentes ecossistemas naturais e sociais em que se insere o Homem, individual e socialmente, num processo de interação que atenda ao desenvolvimento das atividades humanas, à preservação dos recursos naturais e das características essenciais do entorno, dentro das leis da Natureza e de padrões de qualidade definidos.

De acordo com o autor supracitado, a definição acima exposta, se apresenta como "longa e densa" devido à necessidade de compactar, em poucas linhas, uma grande quantidade de noções e conceitos, respeitando a complexidade que a temática requer. Branco (2007) ao tecer considerações sobre a definição de meio ambiente apresentada por Coimbra (op. cit.), ressalta alguns pontos, considerados para ele, fundamentais, a saber:

O meio ambiente não é [...] um sinônimo de ecossistema. Ele inclui o elemento antrópico e tecnológico enquanto que o ecossistema, tal como definido, com suas características homeostáticas de controle e evolução natural não comporta o homem, a não ser em seus estágios primitivos, pois é incompatível com o finalismo e a deliberação característico desta espécie. Porém, isso não implica que o homem não se inscreva ou não constitua um elemento de um sistema maior e mais complexo: o meio ambiente, com um equilíbrio coordenado por uma rede de informações de ordem diferente da que preside o ecossistema, porque emanada de um princípio criador consciente, em permanente integração com o sistema como um todo (BRANCO, op. cit., p. 103).

Ainda é possível registrar algumas definições para meio ambiente na visão de autores de diversas áreas do conhecimento, o que explicita a sua abrangência, bem como a necessidade e importância de uma contextualização pautada em uma visão interdisciplinar ${ }^{3}$ que a temática requer. Para Marques (2005), meio ambiente é a soma total das condições externas circundantes no interior das quais um organismo, um condição, uma comunidade ou um objeto existe, acrescentando-se que, os organismos podem ser parte do ambiente de outros

\footnotetext{
${ }^{3}$ Sobre a abordagem interdisciplinar nas pesquisas ambientais, Godard (2002), ressalta a "resistência" ou mesmo "descrédito" por parte de alguns setores, sendo por vezes, utilizado de forma genérica. Tal fato pode está associado, de acordo com o supracitado autor, ao pouco avanço percebido nas pesquisas de cunho interdisciplinar, o que pode estar relacionado a duas linhas de pensamentos distintas, quais sejam: 1. o fato dos pesquisadores considerarem que a sua área de conhecimento tem total competência de encontrar respostas para o problema investigado; e 2. ou acreditam, os pesquisadores, que as outras áreas do conhecimento são incompetentes para solucionar o problema em questão, fato que está relacionado ao desconhecimento que se tem sobre o campo de trabalho e as competências das diversas ciências. O problema, neste caso, reside no fato de que normalmente se tenta desenvolver projetos levando em consideração o conhecimento disciplinar, o que não se concebe em pesquisas envolvendo a problemática ambiental, devido à complexidade dos fatores que estão inter-relacionados exercendo e sendo influenciado constantemente, o que ressalta a impossibilidade de se estar resolvendo problemas ambientais de forma isolada (disciplinar).
}

REUNIR - Revista de Administração, Contabilidade e Sustentabilidade - Vol. 2, no 4, p.35-57, Set-Dez/2012.

ISSN: 2237-3667 
organismos. Segundo Mendonça (2004), o meio ambiente deixa de receber aquela tradicional visão descritiva/contemplativa por parte da geografia como se fosse um santuário que existe paralelamente à sociedade. $\mathrm{O}$ meio ambiente é visto então como um recurso a ser utilizado e como tal deve ser analisado e protegido, de acordo com suas diferentes condições, numa atitude de respeito, conservação e preservação. De acordo com Coelho (2004), o ambiente ou meio ambiente é social e historicamente construído. Sua construção se faz no processo da interação contínua entre sociedade em movimento e um espaço físico particular que se modifica permanentemente. $\mathrm{O}$ ambiente é passivo e ativo.

Portanto, o meio ambiente por incluir o homem e tudo o que o envolve, constitui-se em um processo dinâmico e em permanente mudança, provocada tanto por fatores externos, sem que haja influência do homem, da flora ou da fauna, como provocada pelas ações do ser humano nos processos transformacionais das matérias primas que o mesmo manipula, bem como das transformações culturais provocadas por mudanças de valores induzida pelo próprio homem. Este meio ambiente em constante transformação pode se alterar para melhor em termos de benefícios aos seres que nele vivem como pode piorar, provocando a destruição destes mesmos seres. Deste modo, o meio ambiente, como construção da mente e ação humana poderá servir de fator engrandecedor ou destruidor da própria humanidade que o manipula.

\subsection{Breve resgate histórico sobre a origem dos problemas ambientais da atualidade}

Os nossos ancestrais, que viveram a cerca de 02 (dois) milhões de anos atrás (homo erectus), se alimentavam através da caça, da pesca e da colheita de onde eles retiravam todos os nutrientes necessários para sua sobrevivência. Tal processo se deu de forma dinâmica, ou seja, as primeiras civilizações eram nômades, não tinham locais de moradia fixos, permanecendo na localidade até o momento que esta tinha suprimentos suficientes para sua alimentação e, consequentemente, sobrevivência. Apesar do processo de exploração do meio ambiente ter se dado de forma mais amena, devido a uma menor população, com menor mobilidade e a inexistência de tecnologias de alto poder destrutivo, verificou-se a extinção de algumas espécies animais, como também, a modificação do meio ambiente através de queimadas e derrubadas de árvores. Ou seja, o homem interferia no meio ambiente o qual estava inserido, modificando-o de modo a atender suas necessidades (PONTING, 1995).

Com o surgimento da agricultura, processo que se desenvolveu de forma inconsciente através das modificações feitas pelo homem ao meio ambiente, foi possível estabelecer moradias fixas (sedentários), o que aumentou, por conseguinte, o crescimento da população uma vez que, existiam mais alimentos disponíveis em pequenos espaços. Fato que deu origem às primeiras cidades.

Tomando por base as discussões levantadas por Clive Ponting (op. cit.) pode-se tecer algumas considerações a esse respeito, a saber:

- a agricultura foi fundamental para fixação do homem nos territórios, o que possibilitou um maior crescimento populacional; inovações tecnológicas (uso do fogo, da roda e da escrita, por exemplo); 
- a agricultura também propiciou o surgimento de batalhas, verdadeiras disputas entre sociedades distintas por terras e recursos naturais, fato que desencadeou o surgimento de armamentos de defesa de modo a garantir a segurança de seus territórios;

- a agricultura foi responsável pelos primeiros impactos ocasionados ao meio ambiente, os quais, com o tempo e amplitude, tornaram-se avassaladores.

Complementando as observações sobre a relação entre os problemas ambientais e o surgimento da agricultura, o autor supramencionado ressalta esta questão enfatizando que, a partir do advento da agricultura, assistiu-se (a humanidade) aos primeiros exemplos de alterações ocasionadas pela ação humana, bem como o seu poder de destruição, se caracterizando como os primeiros exemplos de sociedade que danificavam o ambiental de forma a provocar o seu próprio colapso. Dessa forma, observou-se que, após o advento da agricultura, e o surgimento das primeiras cidades, houve uma grande modificação no processo de organização das antigas civilizações, dando origem a sociedades cada vez mais organizada, hierarquizada e estratificada.

O homem passou a interferir no meio ambiente de forma a atender suas necessidades, transformando o meio natural em meio cultural, e dessa forma, não se enxergando como parte da natureza ${ }^{4}$ em que vive e da qual sobrevive. Desse modo, a exploração ambiental se intensificou, o homem julgando-se senhor da natureza poderia, portanto, manipulá-la como desejasse. Tal ideia, de superioridade, foi posta em prática pelo fato do homem se considerar um ser social, de acordo com Gonçalves (2008, p. 39/40):

Dizer, portanto, que o homem é um ser social como se isso o distinguisse dos demais seres da natureza pode ser uma afirmação altissonante, mas que pouco faz avançar qualquer esforço de diferenciação entre o homem e a natureza, na medida em que os seres vivos, sobretudo os animais, já vivem socialmente. Isso não quer dizer que o homem não seja um animal social, mas que é social porque é animal e os animais vivem socialmente.

De acordo com Branco (2007), a origem da palavra natureza vem do latim natura, que em suas raízes tinha o significado de "ação de fazer nascer". Natureza é, assim, a faculdade geradora, o princípio e o conjunto de tudo que nasce. A palavra natureza corresponde à palavra physis, do grego, que significa nascimento, origem, força, geração.

Para Capra (2004) a natureza é uma complexa teia de relações entre as várias partes de um todo unificado. A "teia da vida" é uma ideia antiga, que tem sido utilizada por poetas, filósofos e místicos ao longo do tempo para transmitir o sentido de entrelaçamento e de interdependência de todos os fenômenos.

Ainda sobre o conceito de natureza e a relação desta com o homem, o Quadro 01 apresenta as diversas concepções sobre natureza criada pelo homem ao logo da história.

\footnotetext{
${ }^{4}$ De acordo com Gonçalves (2008) toda sociedade, toda cultura, cria um determinado conceito de natureza, ao mesmo tempo em que cria e institui suas relações sociais. Neste sentido, o conceito de natureza não é natural, sendo na verdade criado e instituído pelos homens.
}

REUNIR - Revista de Administração, Contabilidade e Sustentabilidade - Vol. 2, no 4, p.35-57, Set-Dez/2012. ISSN: 2237-3667 


\begin{tabular}{|c|c|}
\hline VISÃO & DESCRIÇÃ̃O \\
\hline $\begin{array}{c}\text { Visão sacralizada da } \\
\text { natureza }\end{array}$ & $\begin{array}{l}\text { Conhecer a natureza não era compreendê-la, mas adorá-la. As antropossociedades arcaicas não } \\
\text { sentiam necessidade de explicar a natureza racionalmente, bastava-lhes intuir que a natureza } \\
\text { era dominada por um grande mistério em todas as suas manifestações (panteísmo), ou povoada } \\
\text { por deuses (politeísmo), ou habitada por espíritos (animismo). }\end{array}$ \\
\hline $\begin{array}{l}\text { Visão semi- } \\
\text { sacralizada da } \\
\text { natureza }\end{array}$ & $\begin{array}{l}\text { A invenção da agricultura e da pecuária representou os primeiros passos no processo de } \\
\text { dessacralização do mundo, processo que avançou com a revolução urbana, por volta de } 3.500 \\
\text { a.C. O sagrado não desapareceu, porém o seu recuo diante do profano provocou uma } \\
\text { dicotomia angustiante aos seres humanos, já que a regressão do sagrado impôs-se a fim de } \\
\text { propiciar que as primeiras civilizações pudessem justificar intervenções mais profundas na } \\
\text { natureza. }\end{array}$ \\
\hline $\begin{array}{l}\text { Visão holístico- } \\
\text { interrogatica dos } \\
\text { físicos gregos }\end{array}$ & $\begin{array}{l}\text { Nos séculos VI e V a.C., floresceu no mundo helênico um grupos de pensadores denominados } \\
\text { físicos, porque suas reflexões concentravam-se em torno da origem dos elementos formadores } \\
\text { e do significado da natureza. Adotavam uma postura interrogativa, contemplativa, mas não de } \\
\text { culto à natureza. Para eles, a natureza englobava o mundo em sua totalidade: os seres } \\
\text { humanos, a natureza não-humana e também os deuses. }\end{array}$ \\
\hline $\begin{array}{l}\text { Visão } \\
\text { semidessacralizada } \\
\text { judaico-cristã }\end{array}$ & $\begin{array}{l}\text { Aos poucos, a sacralidade difusa no cosmo concentrou-se numa entidade pessoal que os } \\
\text { judaístas chamam de leveh e num processo denominado história. Se não de todo, pelo menos } \\
\text { em parte o mundo perde seu caráter sacral. A história do povo hebreu-judeu e posteriormente a } \\
\text { da humanidade cristã divorciaram-se da história do cosmo. }\end{array}$ \\
\hline $\begin{array}{c}\text { Visão mecanicista da } \\
\text { natureza }\end{array}$ & $\begin{array}{l}\text { Construída nos seio da cristandade ocidental, a concepção mecanicista da natureza leva às } \\
\text { ultimas consequências os postulados do judaísmo-cristianismo sobre o mundo. A noção de } \\
\text { criação é a dessacralização radical do cosmo. O corpo humano, o dos animais, bem como o } \\
\text { universo não funcionam diferentes de qualquer maquinaria fabricada pelos homens, que se } \\
\text { intitulavam senhores e possuidores da natureza. }\end{array}$ \\
\hline $\begin{array}{l}\text { Visão organicista } \\
\text { contemporânea da } \\
\text { natureza }\end{array}$ & $\begin{array}{l}\text { Na primeira metade do século XIX, a concepção mecanicista da natureza começa a } \\
\text { desmoronar-se. O absolutismo e a certeza são fortemente contestados por teorias como as da } \\
\text { evolução das espécies, da relatividade, do princípio da incerteza entre outras descobertas da } \\
\text { ciência - o homem não pode ser entendido fora de um contexto biológico e ecológico. }\end{array}$ \\
\hline
\end{tabular}

Ao observar o Quadro 01, pode-se inferir que a ideia de dominação do homem sobre a natureza também está presente nas mais diversas culturas e religiões, onde o homem é visto como ser antropocêntrico e superior a qualquer outra forma de vida. De acordo com a religião cristão-judaica, "o homem foi feito à imagem de Deus, tendo, portanto o direito de dominar o mundo". Do mesmo modo, no pensamento pré-cristão, a ideia do homem como guardião do mundo e da natureza também vigorou. Assim como no islamismo e no judaísmo onde a total separação do homem e da natureza ainda persiste (DREW, 2011).

Com isso, verifica-se que a exploração do homem sobre o meio ambiente está fundamentada em preceitos bastante antigos (como os dogmáticos) e culturalmente enraizada numa concepção de eterna supremacia humana sobre todos os outros seres, o que dificulta o desvinculamento do homem deste constante processo de dominação e expropriação dos bens naturais, tendo em vista, que, no seu entender, tal fato é algo natural e intrínseco da sua condição de ser humano.

\subsection{Impacto Ambiental: aspectos conceituais}

Segundo a Resolução CONAMA nº 01/1986, considera-se impacto ambiental qualquer alteração nas propriedades físicas, químicas e biológicas do ambiente causada por qualquer

REUNIR - Revista de Administração, Contabilidade e Sustentabilidade - Vol. 2, no 4, p.35-57, Set-Dez/2012.

ISSN: 2237-3667 
forma de matéria ou energia resultante das atividades humanas que, direta ou indiretamente, afetem: a saúde, a segurança e o bem-estar da população; as atividades sociais e econômicas; a biota; as condições estéticas e sanitárias do ambiente e a qualidade dos recursos ambientais.

Coelho (2004) define impacto ambiental como sendo um processo de mudanças sociais e ecológicas causado por perturbações (uma nova ocupação e/ou construção de um objeto novo: uma usina, uma estrada ou uma indústria) no ambiente. Diz respeito ainda, de acordo com a autora, com a evolução conjunta das condições sociais e ecológicas estimuladas pelos impulsos das relações entre forças externas e internas à unidade espacial e ecológica, histórica ou socialmente determinada. É a relação entre sociedade e natureza que se transforma diferencial e dinamicamente. Os impactos ambientais são descritos no tempo e incidem diferentemente, alterando as estruturas das classes sociais e reestruturando o espaço.

Para Hammes (2004), os impactos das atividades estão relacionados à suas necessidades de existência, que absorve, transforma e produz resíduo. A magnitude dessa relação no espaço depende das questões culturais, de consumo de produtos mais ou menos industrializados, com ou sem embalagens descartáveis e não descartáveis, assim por diante. A complexidade maior ou menor reflete-se no custo das resoluções dos problemas ambientais, de toda a natureza.

De acordo com Valle (2004), até recentemente, a poluição ambiental era estudada apenas por seus efeitos locais e as soluções encontradas eram sempre aplicadas de forma também localizada. O tratamento dos esgotos sanitários e a coleta de lixo urbano para disposição em aterros são dois exemplos clássicos de soluções locais. Agia-se localmente, sem a percepção de que essas ações afetavam globalmente o meio ambiente (VALLE, op. cit., p. 28). Os impactos ambientais estão sendo cada vez mais evidenciados na atualidade. Na medida em que o processo de exploração e apropriação da natureza está se dando de maneira desordenada, sem nenhum controle e com total desrespeito com um bem tão precioso: o meio ambiente. A preocupação está voltada para a acumulação e o crescimento econômico sem levar em consideração o modo que este está sendo feito. Um exemplo é o aumento da geração de resíduos sólidos típico do mundo atual e do processo capitalista no qual estamos inseridos. Neste processo capitalista, o consumo é incentivado como forma de fomentar o desenvolvimento econômico.

\subsection{Ecodesenvolvimento, desenvolvimento sustentável e sustentabilidade: em busca do equilíbrio ambiental.}

A preocupação com o binômio Meio Ambiente x Desenvolvimento, fez com que no ano de 1973 se pensasse numa proposta de desenvolvimento ecologicamente orientado, como forma de minimizar a degradação ambiental, provocada principalmente pelo avanço do processo de industrialização dos países desenvolvidos, surge então à expressão Ecodesenvolvimento para designar uma forma de desenvolvimento pautado na preservação ambiental, sendo um de seus principais colaboradores Ignacy Sachs, o qual formulou os seus princípios básicos, a saber:

$\checkmark$ Satisfação das necessidades básicas;

$\checkmark$ Solidariedade com as gerações futuras;

$\checkmark$ Participação da população envolvida;

$\checkmark$ Preservação dos recursos naturais e do meio ambiente em geral; 
$\checkmark$ Elaboração de um sistema social que garanta emprego, segurança social e respeito a outras culturas; e

$\checkmark$ Programas de educação.

O ecodesenvolvimento visa basicamente uma mudança com relação ao modo de produção e consumo pregado pelo sistema capitalista, que visa apenas os aspectos quantitativos em detrimentos dos qualitativos. Para Sachs (1980, apud BARBIERI, 2003), a ideia de ecodesenvolvimento trazia em si um convite para estudar novas modalidades de desenvolvimento.

Na década de 1980 o termo ecodesenvolvimento passou a ser denominado de Desenvolvimento Sustentável, se tornando o centro das discussões relacionadas com a temática ambiental. O mesmo teve sua divulgação no Relatório Nosso Futuro Comum (Relatório Brundtland), mas apenas na Conferência Rio 92 é que o termo desenvolvimento sustentável tornou-se conhecido publicamente, passando mesmo, em muitos casos, a ser usado como sinônimo para o ecodesenvolvimento.

De acordo com conceituações estabelecidas na Agenda 21 (BRASIL, s/d), o "Desenvolvimento Sustentável" trata-se de um novo modelo de civilização, construído coletivamente, para mudar o padrão de desenvolvimento, com adoção de princípios éticos, de forma que atenda às necessidades básicas atuais, sem prejuízo para as futuras gerações, estabelecendo um contínuo melhoramento da qualidade de vida das comunidades, criando e implantando soluções para combater a degradação ambiental e as desigualdades econômicas e sociais, em que as medidas são aplicadas em uma balança de três pratos - justiça social, proteção ambiental e eficiência econômica.

O desenvolvimento sustentável, consagrado no caput do art. 225 da Constituição Federal, visa o dispositivo à garantia do meio ambiente ecologicamente equilibrado como requisito para a sadia qualidade de vida do homem. Ou seja, o homem necessita do meio ambiente ecologicamente equilibrado para a manutenção de sua vida, da sadia qualidade de vida e mesmo para sua sobrevivência. Daí decorre a necessidade de preservação do ambiente (MARQUES, 2005).

Complementando o pensamento expresso por Marques (2005), Ferreira \& Viola (1996), conceituam uma sociedade sustentável como sendo aquela que mantém o estoque de capital natural ou compensa pelo desenvolvimento do capital tecnológico uma reduzida depleção do capital natural, permitindo assim o desenvolvimento das gerações futuras. Numa sociedade sustentável o progresso é medido pela qualidade de vida (saúde, longevidade, maturidade psicológica, educação, ambiente limpo, espírito comunitário e lazer criativo) ao invés de pelo puro consumo material.

De acordo com Valle (2004), desenvolvimento sustentável significa atender às necessidades da geração atual sem comprometer o direito de as futuras gerações atenderem a suas próprias necessidades. O desenvolvimento sustentável deve, portanto, assegurar as necessidades econômicas, sociais e ambientais, sem comprometer o futuro de nenhuma delas.

Para Michéle Sato ${ }^{5}$ o problema do desenvolvimento sustentável reside na mudança que houve em sua nomenclatura, pois, é difícil imaginar um desenvolvimento econômico que seja

\footnotetext{
${ }^{5}$ Palestra proferida no I Encontro Regional de Educação Ambiental para o Semiárido realizado na cidade de João Pessoa/PB entre os dias 23 a 25 de maio de 2007.
}

REUNIR - Revista de Administração, Contabilidade e Sustentabilidade - Vol. 2, no 4, p.35-57, Set-Dez/2012.

ISSN: 2237-3667 
sustentável no sistema econômico vigente que é o capitalismo, onde a acumulação do lucro será sempre a prioridade máxima. Tal questionamento também é realizado por Camargo (2007) quando a mesma afirma que a expressão desenvolvimento sustentável parece ambígua, unindo duas palavras que a princípio parece não se entrosar - ainda mais quando considera todo o histórico recente do desenvolvimento humano, principalmente desde a revolução industrial, e suas implicações sociais e ambientais negativas.

Toda a distorção social e ambiental que ora se presencia, se deve, em parte, ao crescimento acelerado da economia, que foi impulsionada a expandir-se cada vez mais e a conquistar novos mercados, como se esta expansão a todo custo fosse sinônimo de desenvolvimento, o que não o é, fato que pode ser mais bem explicitado por Furtado (1998, p.47), ao afirmar que: "Quando a capacidade criativa do homem se volta para a descoberta de suas potencialidades, ele se empenha em enriquecer o universo que o gerou, produz-se o que chamamos desenvolvimento. Este somente se efetiva quando a acumulação conduz à criação de valores que se difundem na coletividade" (grifo do autor).

Sobre a questão do desenvolvimento, Gonçalves (2006, p. 62) argumenta que: "Desenvolvimento é o nome-síntese da ideia de dominação da natureza. Afinal, ser desenvolvido é ser humano, é ser industrializado, enfim, é ser tudo aquilo que nos afaste da natureza [...] (grifo do autor)". Ainda de acordo com Gonçalves (2004), sobre o termo desenvolvimento, o autor pontua que des-envolver é tirar o envolvimento (a autonomia) que cada cultura e cada povo mantêm com seu espaço, com seu território; é subverter o modo como cada povo mantém suas próprias relações de homens (e mulheres) entre si e destas com a natureza; é não só separá-los entre si, individualizando-os [...] ao des-envolver, envolve cada um (dos desterritorializados) numa nova configuração societária, a capitalista (grifo do autor).

Resende (apud CAMARGO, 2007) afirma que muitas vezes os termos desenvolvimento e crescimento são utilizados como sinônimos, sendo o crescimento condição indispensável para o desenvolvimento, mas não condição suficiente. Enquanto o crescimento refere-se a incrementos quantitativos, o desenvolvimento implica melhorias qualitativas.

Para Maglio (1999) a busca da sustentabilidade ambiental nos centros urbanos é um dos maiores desafios ambientais do século XXI, sendo amplamente reconhecido que o acúmulo de problemas ambientais não apenas afeta a produtividade das cidades, mas, ainda cobra um ônus maior das populações pobres, sobre as quais recaem os impactos desse processo, dado o precário acesso das mesmas aos serviços básicos de infraestrutura urbana, abastecimento de água, esgotamento sanitário, coleta e disposição adequada dos resíduos, transportes, drenagem e outros serviços.

Neste sentido, se faz necessário que exista uma mudança paradigmática no que concerne ao comportamento do ser humano diante da problemática ambiental instaurada, como destaca Sorrentino (2002, p, 19), ao afirmar que "é preciso despertar em cada indivíduo o sentimento de 'pertencimento', participação e responsabilidade na busca de respostas locais e globais que a temática do desenvolvimento sustentável nos propõe". Dessa forma, seria possível fazer com que cada ser humano soubesse da responsabilidade que tem pelo meio em que vive, passando de agente passivo, que só observa o que acontece ao seu redor, para agente ativo, contribuindo para a preservação do meio ambiente. 
Tal afirmação colocada por Sorrentino (op. cit.) pode ser ainda reforçada por Silva \& Mendes (2005, p. 20/21), quando este autor argumenta que "o desenvolvimento sustentável é de todas as pessoas, por todas as pessoas e para todas as pessoas". Para ele, o conceito de desenvolvimento sustentável é participativo, e, sem pessoas não há desenvolvimento sustentável. $\mathrm{O}$ autor ainda complementa afirmando que "se o desenvolvimento não eliminar a pobreza absoluta, não propiciar a satisfação das necessidades básicas da população em geral, ele não pode ser qualificado de sustentável" (idem).

Quando é exposta a questão da sustentabilidade se ressalta diversas percepções acerca dos múltiplos aspectos, a palavra sustentabilidade gera diferentes conceitos para diferentes tipos de pessoas, políticos, estudantes, agricultores, membros da comunidade, cada pessoa tem uma maneira diferente de enxergar como a sustentabilidade influencia em sua vida, isso é fruto das diferentes necessidades que cada indivíduo possui, tendo em vista que a forma de perceber a natureza e as relações construídas são variadas (AZEVEDO, 2002). Para Armani (2003, citado por CARVALHO, et. al., 2007), a sustentabilidade deve ser entendida com base em dois enfoques complementares, o sistêmico e o gerencial, o sistêmico visa à inserção política, a credibilidade e o fortalecimento da base social das organizações. Já o gerencial focaliza os desafios da gestão e as condições de eficiência das organizações.

Ao lado do conceito de sustentabilidade foi criado também um conceito oposto que é o de insustentabilidade que, para Ferreira (2005), significa a aceleração dos processos biogeoecológicos em função da crescente velocidade humana de consumo, ou seja, o consumismo exacerbado destrói todo um equilíbrio de ecossistema e é necessário evitar a escassez e o esgotamento dos recursos naturais. Podendo este termo ser bem empregado quando se fala da gestão dos resíduos sólidos urbanos, tanto em nível local como nacional, evidenciando as lacunas existentes nos modelos que estão em atividade atualmente.

\section{PROCEDIMENTOS METODOLÓGICOS}

O presente artigo consiste em um ensaio teórico. Para tanto, recorreu-se ao método analítico-descritivo, visto que este pretende analisar o despertar do ser humano para com as causas ambientais, podendo tais questões ser evidenciadas através da organização de eventos de cunho internacional que abordam a temática ambiental; ao tempo que descreve os conceitos de meio ambiente, impacto ambiental e desenvolvimento sustentável, como forma de complementar/auxiliar as discussões aqui propostas.

Como estratégia metodológica, foi realizado um estudo de gabinete, sendo este efetivado através de uma análise bibliográfica em periódicos, sites especializados, anais de eventos científicos, livros, teses e dissertações, objetivando o levantamento de algumas publicações de maior relevância no que concerne ao tema ora pesquisado, tais como Carmargo (2007), Seiffert (2006, 2007), Gonçalves (2004, 2006, 2008), Coimbra (2002), Barbiere (2003), Mendonça (2004), Marques (2005), Branco (2007), dentre outros, e, a partir do mesmo, foi realizada uma análise crítica.

\section{RESULTADOS E DISCUSSÕES}

REUNIR - Revista de Administração, Contabilidade e Sustentabilidade - Vol. 2, no 4, p.35-57, Set-Dez/2012.

ISSN: 2237-3667 


\subsection{O despertar do ser humano para a degradação ambiental: a importância das conferências ambientais}

O despertar das recentes gerações em direção a valores ecológicos tem sido, de acordo com Camargo (2007), denominado de várias formas, tais como: conscientização ecológica ou ambiental, percepção ecológica ou ambiental e sensibilização ecológica ou ambiental. Dessa forma, torna-se difícil conceber qual dessas expressões é a mais apropriada para designar a amplitude desses acontecimentos.

Apesar dos graves problemas ambientais presenciados no século XIX relacionados com a poluição industrial, um dos motivos pelos quais a preocupação ambiental não surgiu naquela época de forma mais efetiva, foi o fato e a degradação ambiental afetar principalmente os trabalhadores, ou seja, a classe pobre da sociedade, sendo somente no século XX que esses problemas alcançaram as classes mais favorecidas (LAGO \& PÁDUA, 1984 apud CAMARGO, op. cit.).

A consciência ambiental conheceu ao longo o século XX, uma grande expansão. Os efeitos devastadores das duas grandes guerras mundiais foram determinantes para que impulsionasse o surgimento da conscientização dos seres humanos a respeito dos impactos ambientais ocasionados pelo poder de destruição bélica das grandes potencias mundiais.

Num primeiro momento, essas mudanças surgiram de forma diferenciada nos países desenvolvidos e foram aos poucos alcançando o restante do mundo ao longo do século XX, constituindo-se num novo movimento social e histórico denominado genericamente de movimento ecológico (CAMARGO, op. cit.).

A primeira ocorrência significativa deste novo movimento ocorreu no campo científico, sendo a década de 1950, marcada pela preocupação ecológica na comunidade científica. Anterior à citada década, pode-se elencar alguns movimentos pontuais de cunho ambientalista. Mas, é a partir da década de 1960 que tais movimentos ganham ênfase, uma vez que, se passa a considerar dentro da problemática ambiental, a relação dos atores sociais e do meio ambiente, passando o mundo a voltar seus olhares para o modo de vida da população mundial.

Com o intuito de tornar pública a problemática ambiental no mundo, esta devido a uma sequência de eventos/acidentes ambientais ocasionados pela utilização inadequada e descuidada de seus recursos, vários eventos em prol do meio ambiente foram realizados, de modo a divulgar a crise ambiental que se instaurara devido ao uso irracional e predatório dos recursos naturais, que muitos julgavam ser inesgotáveis. Desse modo, buscou-se chamar a atenção para o fato de que a qualidade de vida do homem e mesmo a sua sobrevivência a longo prazo no planeta está condicionado a uma boa qualidade ambiental (SEIFFERT, 2007).

Com base na literatura consultada, observaram-se as contribuições realizadas em cada década, as quais corroboraram para a consolidação, ainda em curso, dos fenômenos ambientais vinculados aos sistemas sociais.

\section{a) Década de 1960}

Em 1962, a jornalista e bióloga americana Rachel Carson, publica o livro Silent spring (Primavera silenciosa). Esse livro alertava para o perigo do uso intensivo de DDT (Dicloro 
Difenil Tricloroetano) e outros agrotóxicos nas plantações. Dessa forma, o referido livro foi de fundamental importância na abertura do debate popular em grande escala acerca das questões ambientais. No ano de 1968, um grupo de 30 (trinta) especialistas de diversas áreas do conhecimento, originados de 10 (dez) países, fundou o Clube de Roma, uma organização não governamental, cuja atenção se deteve sobre as questões econômicas e ambientais, debatendo, sobretudo a crise ambiental e o futuro da humanidade. Segundo Odum (1985 apud CAMARGO, 2007, p. 47) "o Clube de Roma foi pioneiro no caminho para a consciência internacional dos graves problemas mundiais".

\section{b) Década de 1970}

A década de 1970 foi marcada pela criação de diversas organizações internacionais, as quais tinham o objetivo de discutir a problemática ambiental que se instaurara mundialmente, como também foi à época do surgimento dos primeiros movimentos ambientalistas organizados, tais como o Greenpeace que nasceu em 1971, 10 anos após a fundação do WWF (Wold Wildlife Fun). Nesta mesma década, foi registrada, pela primeira vez, a preocupação de partidos políticos para com a degradação ambiental. Nesse contexto, diversas leis e regulamentos surgiram com o intuito de preservar o meio ambiente.

O Clube de Roma, em 1972 (quatro anos após sua fundação), divulgou seu primeiro relatório intitulado The limits to growth (Os Limites do Crescimento). Por meio de simulações matemáticas, observaram as projeções de crescimento populacional, poluição e esgotamento dos recursos naturais da Terra, concluindo que, mantidos os níveis de industrialização, poluição, produção de alimentos e exploração dos recursos materiais, o limite de desenvolvimento do planeta seria atingido no máximo em cem anos - o que provocaria uma queda na capacidade industrial e uma repentina diminuição na população mundial, em decorrência da escassez de recursos, poluição, fome e doenças (FRANCO, 2000 apud CAMARGO, op. cit., p, 48).

Desse modo, este relatório ficou conhecido pelo seu cunho alarmista e pela defesa do crescimento zero, o qual tinha como grande defensor Thomas Malthus. Na verdade, o The limits to growth causou um grande impacto, servindo de alerta para à humanidade.

De acordo com MacCormick apud Menezes (1996, p.137), a história das ações da ONU (Organização das Nações Unidas) na área ambiental teve impulso a partir da Primeira Conferencia Mundial sobre Meio Ambiente, em Estocolmo (Suíça) no ano de 1972. Nela, pela primeira vez, representantes de 113 países, 250 organizações não governamentais e vários organismos da ONU se reuniram para discutir as implicações do desenvolvimento econômico na degradação ambiental do Planeta. A tese sobre a necessidade de se buscar um novo horizonte no processo de desenvolvimento ganhou relevância a partir dessa conferência. Ela serviu de base para a criação do Plano de Ação de Estocolmo, o qual estabelecia as bases para uma nova cooperação ambiental internacional. Também resultou da Conferência de Estocolmo a criação do Programa das Nações Unidas para o Meio Ambiente (PNUMA).

De acordo com Seiffert (2007) durante a realização da Conferência de Estocolmo, os países desenvolvidos defendiam um programa internacional voltado para a conservação dos recursos naturais e genéticos do planeta, o que dessa forma, de acordo com os países desenvolvidos, evitaria um grande desastre ambiental no futuro. Em contrapartida, os países

REUNIR - Revista de Administração, Contabilidade e Sustentabilidade - Vol. 2, no 4, p.35-57, Set-Dez/2012.

ISSN: 2237-3667 
em desenvolvimento argumentavam que se encontravam assolados pela miséria, graves problemas de moradia, saneamento básico, enfermidades infecciosas e que necessitavam desenvolver-se economicamente. Para a autora "foi a primeira manifestação dos governos de todo o mundo para discutir as consequências da economia sobre o meio ambiente, quando foi inicialmente delineado o conceito de desenvolvimento sustentável” (IDEM, op. cit., p.12).

Outra contribuição à discussão da problemática ambiental ocorreu com a divulgação da Declaração de Cocoyok, que foi o resultado de uma reunião da Conferencia das Nações Unidas sobre Comércio e Desenvolvimento (UNCTD) e do Pnuma, em 1974. Tal declaração, afirmava que a causa da explosão demográfica era a pobreza, que também gerava a destruição desenfreada dos recursos naturais. A mesma ressaltava que os países industrializados contribuíam para o agravamento dos problemas ambientais devido ao alto índice de consumo e que não existia somente um mínimo de recursos naturais necessários para o bem-estar do indivíduo; existe também um máximo (BRÜSEKE, 2003). Ainda de acordo com o autor "os países industrializados têm que baixar seu consumo e sua participação desproporcional na poluição da biosfera" (IDEM, op. cit., p, 32).

\section{c) Década de 1980}

A década de 1980 foi marcada pela intensificação na formulação de leis regulamentadoras no tocante a poluição, que asseguravam a expansão das atividades industriais, o que aumentou consideravelmente a poluição proveniente dessas atividades. Outro fator desencadeador do agravamento ambiental na década de 1980 é o processo de Globalização, que tinha por objetivo fundamental homogeneizar as civilizações do mundo, colocando como base para este desenvolvimento o estilo de vida norte-americano. O que se verificou, a partir de então, foi uma intensa exploração dos recursos naturais para produção cada vez maior de bens de consumo, fato que gerou outro grave problema, o do o que fazer com os resíduos gerados tanto no processo de produção quanto do próprio consumo.

Também nesta década, teve impulso à formalização e obrigatoriedade da realização de Estudo de Impacto Ambiental e Relatórios de Impactos sobre o Meio Ambiente (EIARIMA), com audiências públicas e aprovações dos licenciamentos ambientais em diferentes níveis de organizações do governo (MOURA, 2002).

Em 1980, foi elaborada a I Estratégia Mundial para a Conservação. A IUCN com a colaboração do PNUMA e do Wold Wildlife Fun (WWF) adota um plano de longo prazo para conservar os recursos biológicos do planeta. No documento aparece pela primeira vez o conceito de desenvolvimento sustentável (DIAS, 2007).

É formada pela ONU a Comissão Mundial sobre o Meio Ambiente e o Desenvolvimento (CMMAD), em 1983, que tinha por objetivo examinar as relações entre o meio ambiente e o desenvolvimento e apresentar propostas viáveis para a solução dos problemas existentes. Em 1984, surge no Canadá, o Programa de atuação Responsável (Responsible Core Program), considerado o primeiro modelo de gestão ambiental formal (SEIFFERT, 2007).

No ano de 1987, foi lançado o relatório Brundtland, também conhecido como Nosso Futuro Comum (Our common future), fruto dos resultados de trabalho da Comissão Mundial (da ONU) sobre Meio Ambiente e Desenvolvimento (UNCED). Tal relatório parte de uma 
visão complexa das causas dos problemas socioeconômicos e ecológicos da sociedade global. Ele sublinha a interligação entre economia, tecnologia, sociedade e política e chama também a atenção para uma nova postura ética, pautada na responsabilidade tanto entre gerações quanto entre os membros contemporâneos da sociedade atual (BRÜSEKE, op. cit.). Em resumo, pode-se dizer que, o Nosso Futuro Comum registrou os sucessos e as falhas do desenvolvimento mundial, assim como, divulgou a ideia de um desenvolvimento pautado na sustentabilidade dos recursos.

\section{d) Década de 1990}

A década de 1990 ficou conhecida, de acordo com Camargo (2007), como sendo aquela em que houve um grande impulso com relação à consciência ambiental na maioria dos países, principalmente no que concerne as mudanças climáticas e ao aquecimento global.

A expressão qualidade ambiental passou a fazer parte do cotidiano das pessoas. Muitas empresas passaram a se preocupar com a racionalização do uso de energia e de matériasprimas, além de maior empenho e estímulos à reciclagem e reutilização, evitando desperdícios (MOURA, op. cit.).

Em outubro de 1990, em Genebra, ocorre a Conferência Mundial sobre o Clima, promovida pela Organização Mundial de Meteorologia, em que se discutiu a questão dos desequilíbrios climáticos globais (DIAS, 2003).

Em 1991, foi elaborada a norma internacional de proteção ambiental ISO (International Organization for Standardization) 14001, a qual somente foi proposta como referência para o processo de gestão ambiental organizacional durante a ECO 92. A série de normas ISO 14000 apresentam importante função dentro de um contexto micro, em nível organizacional, no que concerne a questão ambiental da empresa, a ISO 14001, particularmente, estabelece uma base comum para a gestão ambiental eficaz no mundo inteiro, sendo aplicável a organizações com os mais variados perfis (SEIFFERT, 2006).

No ano de 1992, na cidade do Rio de Janeiro, 20 (vinte) anos após a Conferência de Estocolmo, foi realizada a II Conferência das Nações Unidas sobre Meio Ambiente e Desenvolvimento (Cnumad), também conhecida como Rio-92, Eco-92 ou Cúpula da Terra. A mesma foi saudada como sendo o mais importante e promissor encontro planetário do século XX. O referido evento, contou com a participação de representantes e governantes de 179 países, os quais durante o transcorrer do evento, discutiram, analisaram e aprovaram uma série de documentos referentes a temas ambientais bastante relevantes. Dentre esses documentos podem ser citados, a Declaração do Rio de Janeiro sobre o meio ambiente e o desenvolvimento, a Convenção sobre mudanças climáticas, a Declaração de Princípios sobre florestas e a Agenda 21. No que se refere ao último documento, este representa um programa de ação baseado num documento de 40 capítulos, que constitui a mais abrangente tentativa já realizada de promover, em escala planetária, um novo padrão de desenvolvimento, denominado "desenvolvimento sustentável". O termo "Agenda 21" foi usado no sentido de intenções, desejo de mudança para esse novo modelo de desenvolvimento para o século XXI.

A Agenda 21 global pode ser definida como um instrumento de planejamento para a construção de sociedades sustentáveis, em diferentes bases geográficas, que concilia métodos de proteção ambiental, justiça social e eficiência econômica. Quanto a Agenda 21 Brasileira, 
esta é um instrumento de planejamento participativo para o desenvolvimento sustentável do país, resultado de uma vasta consulta à população brasileira. Foi coordenado pela Comissão de Políticas de Desenvolvimento Sustentável e Agenda 21 (CPDS); construído a partir das diretrizes da Agenda 21 Global; e entregue à sociedade, por fim, em 2002. Por último, tem-se a Agenda 21 Local que é originada com base em um processo de planejamento participativo de um determinado território que envolve a implantação, ali, de um Fórum de Agenda 21. Composto por governo e sociedade civil, o Fórum é responsável pela construção de um Plano Local de Desenvolvimento Sustentável, que estrutura as prioridades locais por meio de projetos e ações de curto, médio e longo prazos. No Fórum são também definidos os meios de implementação e as responsabilidades do governo e dos demais setores da sociedade local na implementação, acompanhamento e revisão desses projetos e ações ${ }^{6}$.

A Primeira Conferência das Partes para a Convenção sobre Mudanças Climáticas realizou-se em 1995, em Berlim. Em junho de 1997, líderes dos oito países mais ricos do globo (G8), responsáveis por metade da emissão de gases causadores do efeito estufa, reuniram-se em Denver (Colorado) para formular um acordo de redução de emissões de poluentes (DIAS, 2007). O protocolo de Kyoto foi assinado na $6^{\mathrm{a}}$ Conferencia das Partes da Convenção das Nações Unidas sobre Mudanças Climáticas (COP6), realizada no Japão, em 1997, após discussões que se estenderam desde 1990 (SEIFFERT, 2007).

Ainda no ano de 1997, no Rio de Janeiro, foi realizado um encontro não-oficial denominado Rio+5, com o intuito de avaliar o efetivo andamento das decisões da Agenda 21. Esse encontro foi organizado pela entidade "Amigos da Terra" e coordenado pelo então coordenador da Rio-92, Maurice Strong. Ao final do encontro, concluiu-se que muito pouco havia sido realizado nos últimos 05 (cinco) anos que se seguiram a Rio-92.

\section{e) Século XXI}

Foi realizado no ano de 2002, em Johannesburgo, África do Sul, o evento da Cúpula Mundial sobre o Desenvolvimento Sustentável (CMDS), conhecida como Rio+10, já que a mesma teve como objetivo avaliar os avanços na situação do ambiente global em função de medidas que foram adotadas na Rio-92 (DIAS, 2003). Deste evento resultaram dois documentos: a Declaração Política e o Plano de Implementação. A Declaração política tem como Título "O Compromisso de Johannesburgo por um Desenvolvimento Sustentável".

No ano de 2007, se desenrolou o Painel Intergovernamental de Mudanças Climáticas (Intergovernmental Panel of Climatic Changes - IPCC), em Paris, com participação de 500 especialistas. As informações contidas no relatório divulgado pelo IPCC confirmam várias previsões alarmistas sobre as consequências do aquecimento global sobre os ecossistemas e a qualidade de vida do homem.

Afora a realização do IPCC, diversas outras conferências foram realizadas neste século, com fins de discutir alternativas para minorar os impactos ambientais, decorrentes do modelo de desenvolvimento vigente, no clima mundial. Sendo estas denominadas de Conferência das Partes - COP. Dentre as conferências já realizadas, merece destaque a COP-15, que aconteceu no ano de 2009 tendo como sede a cidade de Copenhague, na Dinamarca. Apesar

\footnotetext{
${ }^{6}$ Informações disponíveis no site do Ministério do Meio Ambiente: http://www.mma.gov.br/responsabilidadesocioambiental/agenda-21. Acesso em: 20 de outubro de 2012.
}

REUNIR - Revista de Administração, Contabilidade e Sustentabilidade - Vol. 2, no 4, p.35-57, Set-Dez/2012.

ISSN: 2237-3667 
de ter sido considerada como uma das reuniões sobre mudanças climáticas mais importantes da história, a mesma não conseguiu alcançar os objetivos pretendidos, visto que esta não estabeleceu metas para a redução de gases de efeito-estufa, deixando muitos líderes insatisfeitos com o texto final, por considerá-lo insuficiente, haja vista que este teve um caráter meramente informativo, não propondo objetivos e/ou metas para a manutenção do Protocolo de Kyoto, por exemplo.

Mais recentemente, no ano de 2011, foi realizada a COP-17 na cidade de Durban, África do Sul. De acordo com especialistas, esta foi considerada a conferência mais importante sobre o clima desde a criação do protocolo de Kyoto, no ano de 1997. Após o término da referida conferência, obteve-se como resultado um texto de uma página e meia, o qual foi denominado de Plataforma de Durban, neste documento algumas questões foram definidas, dentre elas, a de elaborar até o ano de 2015 um marco legal para a ação contra a mudança climática; a prorrogação do Protocolo de Kyoto além de 2012, e a determinação do início das atividades do Fundo Verde para o Clima - estipulado um ano antes, na COP-16 realizada em Cancún.

No ano de 2012, vinte anos depois da Conferência das Nações Unidas sobre Meio Ambiente e Desenvolvimento (Eco-92), a cidade do Rio de Janeiro sediou novamente a Conferência das Nações Unidas sobre Desenvolvimento Sustentável, à chamada Rio+20, realizada no período de 13 a 22 de junho. A mesma visava renovar o engajamento dos líderes mundiais com o desenvolvimento sustentável do planeta, que tinha sido firmado na Rio 92.

Durante o período em que foi realizada, centenas de eventos foram desenvolvidos no período que antecedeu e durante a Rio+20, incluindo mais de 500 eventos oficiais e paralelos no Centro de Convenções Riocentro, onde a Conferência foi realizada. A Rio+20, pela ampla participação, pode ser considerada a maior Conferência da Organização das Nações Unidas (ONU) já realizada, com ampla participação de líderes dos setores privado, do governo e da sociedade civil, bem como funcionários da ONU, acadêmicos, jornalistas e o público em geral.

Trigueiro (2012), sobre a Rio+20, relata que depois de cinco dias reunidos na Pontifícia Universidade Católica do Rio (PUC-RJ), 500 cientistas de 75 países - seis deles Prêmios Nobel - produziram um relatório contundente em que resumem a situação do planeta. Entre outras informações, eles dizem que "há evidências científicas convincentes de que o atual modelo de desenvolvimento está minando a capacidade de o planeta responder às agressões do homem". Manifestam preocupação com o fato de que "os níveis de produção e de consumo poderão causar mudanças irreversíveis e catastróficas para a humanidade". Mas asseveram que "temos conhecimento e criatividade para construir um novo caminho. Entretanto, é preciso correr contra o tempo".

\section{CONSIDERAÇÕES FINAIS}

Diante do exposto, pode-se dizer que se a consciência ambiental cresceu consideravelmente a partir da segunda metade do século XX, a percepção dos problemas ambientais ocorreu de modo diferenciado ao longo do tempo. Comungamos com Barbieri (2003, p.15), quando o autor ressalta que "a preocupação com os problemas ambientais decorrentes dos processos de crescimento e desenvolvimento deu-se lentamente e de modo

REUNIR - Revista de Administração, Contabilidade e Sustentabilidade - Vol. 2, no 4, p.35-57, Set-Dez/2012.

ISSN: 2237-3667 
muito diferenciado entre diversos agentes, indivíduos, governos, organizações internacionais e entidades da sociedade civil".

É bem verdade que ainda há muito que se caminhar, principalmente quando se fala na efetivação das diversas metas e propostas para um desenvolvimento sustentável que vem, ao logo das décadas, compondo os diversos documentos resultantes das conferências ambientais realizadas com maior efetividade a partir da década de 1990, sendo este período reconhecido como um marco internacional para o debate ambiental, especialmente devido à publicação da Agenda 21, importante instrumento de discussão em torno da temática ambiental, com vistas a um novo modelo de desenvolvimento para o séc. XXI, estando este pautado em uma sociedade sustentável.

No que se reporta a Rio+20, é bem verdade que esta deixou uma sensação de retrocesso, em virtude da ausência de metas mais ambiciosas do ponto de vista de ações mais eficazes e eficientes em favor da proteção ambiental, uma vez que esta proteção continua sendo vista como um grande empecilho ao desenvolvimento econômico das nações. Mas, há que se reconhecer que a citada conferência foi considerada uma das maiores já realizadas em prol do meio ambiente, e se de fato não obteve-se ações mais concretas, esta serviu, ao menos, para ampliar a visibilidade das questões ambientais em âmbito internacional.

Nesta perspectiva, o desenvolvimento de iniciativas em prol da manutenção e do equilíbrio ambiental são muito necessárias, principalmente quando analisa-se o padrão de consumo vigente mas, ressalta-se que tais iniciativas tem que buscar incluir todos os seguimentos da sociedade nas tomadas de decisões, como forma de se obter resultados que sejam equitativos, justos e sustentáveis.

A conscientização e o ativismo de todos os setores da sociedade é parte necessária para que o sucesso seja obtido no que concerne ao desenvolvimento sustentável, uma vez que ele se expressa em ações que devem ser tomadas em todas as esferas da sociedade, sejam elas de caráter individual, tais como o consumo consciente, até as de níveis governamentais, com a elaboração de leis que obriguem as empresas industriais e o setor de serviços a se pautarem por normas legais que minimizem o impacto ambiental das suas atividades e os responsabilizem pela compensação de quaisquer impactos deletérios remanescentes.

Por fim, ressalta-se que quaisquer iniciativas que visem à qualidade ambiental, através de ações e atitudes conscientes e coerentes com a atual crise ambiental, somente serão concretizadas quando o bem estar social se sobrepor aos interesses políticos, uma vez que tais ações são implementadas, necessariamente, pelos gestores e, cabem a estes, a condução de ações que promovam um ambiente equilibrado com vista a obtenção de uma sadia qualidade de vida, conforme preconizado no Art. 225 da Constituição Federal do Brasil promulgada em 1988.

\section{REFERÊNCIAS}

AZEVEDO, R. A. B. A sustentabilidade da agricultura e os conceitos de sustentabilidade estrutural e conjuntural. Revista Agricultura Tropical. Cuiabá, v.6, n.1, p. 9-42, 2002.

BARBIERI, J. C. Desenvolvimento e Meio Ambiente: As Estratégias de Mudanças da Agenda 21. 6 ed. Petrópolis, RJ: Vozes, 2003. 
PEREIRA, S. S.; CURI, R. C. Meio Ambiente, Impacto Ambiental e Desenvolvimento...

BRANCO, S. M. Ecossistêmica: uma abordagem integrada dos problemas do meio ambiente. 2 ed. São Paul: Edgard Blücher, 2007.

BRASIL, Ministério do Meio Ambiente. Caderno de Debates - Agenda 21 e Sustentabilidade: a agenda 21, o semiárido e a luta contra a desertificação. MMA. Secretária de Políticas para o Desenvolvimento Sustentável. s/d. disponível em: www.mma.gov.br/estruturas/agenda21/_arquivos/cad_amarelo.pdf. Acesso em: 20 de março de 2012 .

BRÜSEKE, F. J. O Problema do Desenvolvimento Sustentável. In: CAVALCANTI, C. (org.). Desenvolvimento e Natureza: estudos para uma sociedade sustentável. 4 ed. São Paulo: Cortez; Recife, PE: Fundação Joaquim Nabuco, 2003. p. 29-40.

CAMARGO, A. L. de B. Desenvolvimento sustentável: dimensões e desafios. 3 ed. Campinas, SP: Papirus, 2007.

CAPRA, F. A Teia da Vida: uma nova compreensão dos sistemas vivos. EICHEMBERG, N. R. (Trad.). 9 ed. São Paulo: Editora Cultrix, 2004.

CARVALHO, D. N., et. al. Gestão e sustentabilidade: um estudo em multicasos em ONGs ambientalistas de Minas Gerais. Revista de Gestão Social e Ambiental. mai-ago 2007, v.1, n.2, p. $74-92$.

COELHO, M. C. N. Impactos Ambientais em Áreas Urbanas: teorias, conceitos e métodos de pesquisa. In: GUERRA, A. J. T. \& CUNHA, S. B. da. (Orgs.). Impactos Ambientais Urbanos no Brasil. 2 ed. Rio de Janeiro: Bertrand Brasil, 2004, 416p., p.19-45.

COIMBRA, J. de A. A. O outro lado do meio ambiente: uma incursão humanística na questão ambiental. Campinas: Millennium, 2002.

CONAMA, Conselho Nacional do Meio Ambiente. Resolução No 001, de 23/01/86. Dispõe sobre critérios básicos e diretrizes gerais para o Relatório de Impacto Ambiental - RIMA. Disponível em: http://www.mma.gov.br/port/conama/legiabre.cfm?codlegi=23. Acesso em: 20 de maio de 2012.

DIAS, G. F. Educação Ambiental: Princípios e práticas. 8 ed. São Paulo: Gaia, 2003.

DIAS, R. Gestão Ambiental: responsabilidade social e sustentabilidade. São Paulo: Atlas, 2007.

DREW, D. Processos Interativos Homem-Meio Ambiente. 6 ed. Tradução de João Alves os Santos. Rio de Janeiro: Bertrand Brasil, 2011.

REUNIR - Revista de Administração, Contabilidade e Sustentabilidade - Vol. 2, no 4, p.35-57, Set-Dez/2012. ISSN: 2237-3667 
PEREIRA, S. S.; CURI, R. C. Meio Ambiente, Impacto Ambiental e Desenvolvimento...

DULLEY, R. D. Noção de natureza, ambiente, meio ambiente, recursos ambientais e recursos naturais. In: Agric. São Paulo, São Paulo, v. 51, n. 2, p. 15-26, jul./dez. 2004. Disponível em: http://www.iea.sp.gov.br/out/publicacoes/pdf/asp-2-04-2.pdf. Acesso: 10/08/2011.

ELY, A. Economia do meio ambiente. 4. ed. Porto Alegre: Fundação de Economia e Estatística. Siegfried Emanuel Coser, 1998.

FERREIRA, S. de L. Os "catadores do lixo" na construção de uma nova cultura: a de separar o lixo e da consciência ambiental. 2005. Disponível em: <http://br.geocities.com/mcrost07/20050826a_os_catadores_do_lixo_na_construcao_de.>. Acesso em: 02 de maio de 2010.

FERREIRA, L. da C. \& VIOLA, E. (orgs.). Incertezas de sustentabilidade na globalização. Campinas: Unicamp, 1996.

FRANCO, T. \& DRUCK, G. Padrões de industrialização, riscos e meio ambiente. Revista Ciência e Saúde Coletiva, v. 3, n. 2, 1998, p. 61-72.

FURTADO, C. O Capitalismo Global. São Paulo: Ed. Paz e Terra, 1998.

GODARD, O. A relação interdisciplinar: problemas e estratégias. In: VIEIRA, P. F., WEBER, J. Gestão de recursos naturais renováveis e desenvolvimento: novos desafios para a pesquisa ambiental. São Paulo: Córtex, 2002. p. 321- 360.

GONÇALVES, C. W. P. O Desafio Ambiental. Rio de Janeiro: Record, 2004.

GONÇALVES, C. W. P. A Globalização da Natureza e a Natureza da Globalização. Rio de Janeiro: Civilização Brasileira, 2006.

GONÇALVES, C. W. P. Os (des)caminhos do meio ambiente. 14 ed. São Paulo: Contexto, 2008. (Temas atuais).

HAMMES, V. S. Efeitos da Diversidade e da Complexidade do Uso e Ocupação do espaço Geográfico. In: HAMMES, V. S. (Editora Técnica). JULGAR - Percepção do Impacto Ambiental. Vol. 4/Embrapa. São Paulo: Editora Globo, 2004. 223p. p. 35-39.

KLOETZEL. K. O que é meio ambiente. 2 ed. São Paulo: Brasiliense, 2009.

MAGLIO, I. C. Cidades Sustentáveis: preservação, controle e mitigação de impactos ambientais em áreas urbanas. In: PHILIPPI, JR. A., MAGLIO, I. C., COIMBRA, J. A. A. Municípios e Meio Ambiente: perspectivas para a municipalização da gestão ambiental no Brasil. São Paulo: ANAMA, 1999. p. 80-85. 
PEREIRA, S. S.; CURI, R. C. Meio Ambiente, Impacto Ambiental e Desenvolvimento...

MARÇAL, M. da P. V. Educação ambiental e representações sociais de meio ambiente: uma análise da prática pedagógica no ensino fundamental em Patos de Minas - MG (20032004). Uberlândia, 2005.

MARQUES, J. R. Meio Ambiente Urbano. Rio de Janeiro/RJ: Ed. Forense Universitária. 2005.

MENDONÇA, F. de A. Geografia e Meio Ambiente. 7 Ed. São Paulo: Contexto, 2004.

MENEZES, C. L. Desenvolvimento Urbano e Meio Ambiente: a experiência de Curitiba. Campinas/SP: Papirus, 1996.

MOURA, L. A. A. Qualidade e gestão ambiental: sugestões para implantação das normas ISSO 14000 nas Empresas. 3. Ed. São Paulo: Juarez de Oliveira, 2002.

PÁDUA, J. A. Bases teóricas como da História Ambiental . In: Estud. av. [online]. 2010, vol.24, n.68, pp 81-101.

PONTING, C. Uma História Verde do Mundo. Tradução de Ana Zelma Campos. Rio de Janeiro: Civilização Brasileira, 1995.

SEIFFERT, M. E. B.. ISO 14001: Sistemas de Gestão Ambiental: implantação objetiva e econômica. São Paulo: Atlas, 2006.

SEIFFERT, M. E. B. Gestão Ambiental: instrumentos, esferas de ação e educação ambiental. São Paulo: Atlas, 2007.

SGARBI, V. S et. al. Os Jargões da Sustentabilidade: uma Discussão a partir da Produção Científica Nacional, engema 2008.

SILVA, C. L. S. \& MENDES, J. T. G. (orgs.). Reflexões sobre Desenvolvimento Sustentável: agentes e interações sobre a ótica multidisciplinar. Petrópolis, RJ: Vozes, 2005.

SORRENTINO, M. Desenvolvimento Sustentável e Participação: algumas reflexões em voz alta. In: CASTRO, R. S. de. Et. al. (orgs.). Educação Ambiental: repensando o espaço da cidadania. São Paulo: Cortez, 2002.

TRIGUEIRO, A. Rio+20 sem ciência. Disponível em: < http://g1.globo.com/platb/mundosustentavel/2012/06/16/rio20-sem-ciencia/>. Acesso em: 30 de junho de 2012.

VALLE, C. E. Qualidade Ambiental: ISO 14000. 5 Ed. São Paulo/SP: SENAC, 2004.

WALDMAN, M. Natureza e sociedade como espaço de cidadania. In: PINSKY. J.; PINSKY.

C. B. (Org.). História da cidadania. São Paulo: Contexto, 2003. p. 545-561. 


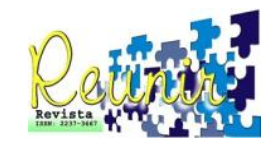

PEREIRA, S. S.; CURI, R. C. Meio Ambiente, Impacto Ambiental e Desenvolvimento... 